\title{
Formation of a unidirectional gradient structure in titanium alloy using reversible hydrogen alloying
}

O. N. Gvozdeva, Associate Professor ${ }^{1}$, Candidate of Engineering Sciences, e-mail: gon7133@mail.ru

A. V. Shalin, Associate Professor ${ }^{1}$, Candidate of Engineering Sciences, e-mail: priest87@gmail.com

A. S. Stepushin, Post-Graduate Student ${ }^{1}$, e-mail: 69stee/@gmail.com

G. T. Zaynetdinova, Head of a Laboratory ${ }^{1}$, e-mail: gzaynetdinova@gmail.com ${ }^{1}$ The Federal State Budgetary Educational Institution of Higher Education Moscow Aviation Institute (National Research
University), Moscow, Russia.

\begin{abstract}
The paper discusses the use of titanium alloys, for example, the VT6 alloy, for local armoring, which, with their minimum specific surface area, should provide high absorption of impact energy and a slow rate of crack propagation. It is shown that the achievement of such contradictory requirements is possible due to the creation of a directional gradient structure in the semi-finished product, which varies linearly from one side of the surface to the opposite. It is shown that the creation of such structures is possible due to the combined use of thermal and chemical-thermal treatments. The regularities of the formation of a unidirectional gradient structure in plates made of titanium alloy VT6 by means of thermal hydrogen treatment are investigated. It has been established that oxide and nitride coatings formed at isothermal holdings for 4 hours and 30 minutes, respectively, work effectively as a barrier to hydrogen penetration. It has been found that the barrier oxide and nitride coatings most effectively perform the "protective" function when hydrogen is introduced up to $0.4 \%$. It is shown that by varying the concentration of the introduced hydrogen, it is possible to change the depth of its diffusion penetration and, accordingly, the structure in the near-surface layers. It is shown that the finely dispersed structure formed on the surface of semi-finished products gives it increased strength characteristics, and the coarse-lamellar structure in the center of the samples provides good toughness and slows down the rate of crack propagation. It has been found that the barrier properties of the oxide coating during the thermal hydrogen treatment of large-sized items are slightly inferior to the same properties of the nitride coating. It is shown that the creation of a unidirectional gradient structure in plates made of VT6 alloy with a thickness of $12 \mathrm{~mm}$ provides them with good dynamic resistance when fired with $5.45 \mathrm{~mm}$ high penetration ammunition and $7.62 \mathrm{~mm}$ with a steel core bullet.
\end{abstract}

Key words: titanium alloy, gradient structure, oxide, nitride, hydrogen, initial velocity, mass, hardness, dynamic resistance, impact strength.

DOI: $10.17580 / \mathrm{nfm} .2021 .01 .05$

\section{Introduction}

$\mathrm{W}$ Then aircrafts perform tasks at low altitudes, there is a possibility of being hited by small arms, which poses a threat to the life of the crew. To ensure its safety, it is necessary to armour the cockpit, but this should not cause a change in the aircraft performance characteristics and ease of operation.

Nowdays, developers in this area are Russian (Russian Helicopters), American (Armour of America, AMRDEC, TenCate Advanced Armour), British (Permali Gloucester), Indian (MKU Airborne Systems), Australian (CCA Protect) companies that mainly use traditional materials with high density for local armoring, which significantly increases the weight of aircraft and reduces their technical and aerodynamic properties [1-2]. Therefore, it is promising to create the same or improved protection, but with the use of substantially lighter materials, such as titanium alloys.

The heaviest demands that are imposed on the materials for local armoring are high blow energy absorption and slow rate of crack propagation with their minimum specific surface area [3-5]. The achievement of these requirements is possible by creating in the semi-finished product a directional gradient structure, which varies linearly from one side of the surface to the opposite one [6-7]. One of the feasible effective methods for creating such a structure in titanium alloys is thermal hydrogen treatment, based on reversible alloying with hydrogen [8-11]. In [12-14], it is shown that thermal hydrogen treatment helps to make "bulk" gradient structures in which its transformation proceeds concurrently and uniformly from all sides to a certain depth. However, in case of the unidirectional gradient structure formation, it is necessary to leave only one side for intake of hydrogen and to protect the rest.

Previous investigations have shown that the oxide or nitride coatings can be used as protective layers [15-16]. Their properties have been determined and a common principle of operation of such protective coatings in the formation of unidirectional gradient structures has been shown. The present paper is a continuation of research conducted in this direction.

The object of this work was to conduct a comparative analysis of the parameters and properties of the unidirectional gradient structures formed by thermal hydrogen treatment in a VT6 alloy plate with different types of protective coating. 
Table 1

Chemical composition of VT6 two-phase titanium alloy

\begin{tabular}{|c|c|c|c|c|c|c|c|c|}
\hline \multirow[t]{2}{*}{ VT6 Alloy } & \multicolumn{2}{|c|}{$\begin{array}{l}\text { Alloying elements, } \\
\text { (\% by weight })^{\star}\end{array}$} & \multicolumn{6}{|c|}{$\begin{array}{c}\text { Impurities, } \\
\text { not more than (\% by weight) }\end{array}$} \\
\hline & $\mathrm{Al}$ & V & $\mathrm{Fe}$ & $\mathrm{H}$ & $\mathrm{C}$ & 0 & $\mathrm{~N}$ & $\mathrm{Zr}$ \\
\hline The test plate & 5.8 & 4.1 & 0.2 & 0.001 & 0.03 & 0.11 & 0.02 & 0.18 \\
\hline According to GOST 19807-91 & $5.3-6.8$ & $3.5-5.3$ & 0.6 & 0.015 & 0.10 & 0.20 & 0.05 & 0.30 \\
\hline
\end{tabular}

Table 2

Mass-velocity parameters of ammunition (striker) [14-15]

\begin{tabular}{|c|c|c|c|c|}
\hline $\begin{array}{c}\text { Caliber / Name } \\
\text { of the } \\
\text { ammunition }\end{array}$ & $\begin{array}{c}\text { Bullet } \\
\text { hardness, } \\
\text { HRC }\end{array}$ & $\begin{array}{c}\text { Bullet } \\
\text { mass, } \\
\text { g }\end{array}$ & $\begin{array}{c}\text { Initial velocity } \\
\text { of the } \\
\text { bullet, m/s }\end{array}$ & $\begin{array}{c}\text { Bullet } \\
\text { energy, } \\
\mathrm{J} / \mathrm{mm}^{2}\end{array}$ \\
\hline $5.45 \mathrm{~mm} / \mathrm{HP}$ & 60 & 3.6 & 880 & 1400 \\
\hline $5.45 \mathrm{~mm} / \mathrm{AP}$ & 75 & 3.7 & 880 & 1430 \\
\hline $7.62 \mathrm{~mm} / \mathrm{SC}$ & 30 & 7.9 & 725 & 2070 \\
\hline $7.62 \mathrm{~mm} / \mathrm{API}$ & 60 & 7.9 & 740 & 2150 \\
\hline $.338 \mathrm{LM}$ & 5 & 17 & 900 & 6870 \\
\hline
\end{tabular}

\section{Materials and methods of research}

The research has been conducted on a hot-rolled plate made of VT6 titanium alloy, which is widely used both in Russia (VT6c, VT6k, VT6ch) and abroad (Ti64, IMI318, TC4, SAT-64) [17]. The plate chemical composition is shown in Table 1 and meets the requirements of the State standard GOST 19807-91. Samples with the size of $15 \times 20 \times 12.5 \mathrm{~mm}$ for metallographic studies and hardness measurement have been cut out of a plate $12.5 \mathrm{~mm}$ thick.

Thermal treatment in air atmosphere and in vacuum has been carried out in electric furnaces SNOL2.2,5.1,8/ 10-I3 and Vega-3M, respectively. Deposition of titanium nitride has been implemented in a Bulat-6 ("Булат-6") plant. Hydrogen addition has been fulfilled on a Sieverts unit in pure molecular hydrogen environment. The introduced hydrogen concentration has been determined by weight increments with an accuracy of $0.0001 \mathrm{~g}$. The macrostructure has been studied using a Nikon D5200 digital camera with an AF-2875/2. 8 lens. The microstructure was examined using an AXIO Observer.A1m optical microscope at magnifications from 25 to 450 times. Analysis of the resultant images has been carried out using ImageExpert Pro 3 software package.

The depth of hydrogen penetration was determined on metallographic thin sections by change in Vickers microhardness on a MicroMet 5101 hardness testing machine with a $50 \mathrm{~g}$ load. Rockwell hardness was determined on a Macromet 5100T device in accordance with GOST 9013-59.

Short-term properties at room temperature were determined during tensile tests on a TIRAtest 2300 universal tearing machine in accordance with GOST 1497-84. To determine the strength and ductility, standard cylindri- cal samples of type IV, M12 were made of the plate. The impact strength was determined on JB-300B pendulum copra according to the State standard GOST 9454-78 on samples with U-shaped notches. The notch was applied to the opposite side with the transformed structure.

The ballistic properties were tested on the plates at distances of 10 and 100 meters using a submachine gun, a machine gun and a sniper rifle in accordance with the State standards GOST R 50744-95 and GOST 50963-96 [18-19]. During examination there were used $5.45 \mathrm{~mm}$ ammunition with high penetration (HP) and armorpiercing (AP) bullets; $7.62 \mathrm{~mm}$ ammunition with a steel core (SC) bullet and an armor-piercing incendiary (API) bullet; caliber .338 Lapua Magnum (LM) with a full metal jacket bullet (Table 2).

\section{Results and discussion}

At the first stage of the work, the introduced hydrogen concentration influence on the regularities of the structure formation in the process of unidirectional hydrogenating annealing has been studied. To create barrier coatings on the samples, some of them have been subjected to high-temperature four-hour air atmosphere oxidation in furnaces at a temperature of $900{ }^{\circ} \mathrm{C}$, and the rest was covered with a nitride coating at a temperature of $400{ }^{\circ} \mathrm{C}$ [20-22]. One side of the samples has been mechanically released from oxide or nitride coating prior to the start of hydrogenating annealing. The choice of temperature and concentration conditions of hydrogenating annealing was made based on fundamental laws of hydrogen interaction with titanium alloys and taking into account the mechanics of unilateral absorption of hydrogen by the semi-finished product $[8-9,13]$.

Thus, in this work, hydrogen addition was performed at a temperature of $800{ }^{\circ} \mathrm{C}$ in the concentration range from $0.3 \%$ to $0.6 \%$ of hydrogen (by weight). At the end of the hydrogen absorption process, accelerated cooling was performed to ensure its inhomogeneous distribution over the sample cross-section.

Macroanalysis of the samples has showed that a pronounced structural boundary (Fig. 1, $a, c$ ) is observed at hydrogen amount of $0.3 \%$ and $0.4 \%$ just on the side free from the oxide or nitride barrier coating. At the samples being hydrogen-charged to amount of $0.5 \%$ and $0.6 \%$, this boundary becomes cilcular, which may indicate the penetration of hydrogen from the sides protected by the barrier coating as well (Fig. 1, $b, d$ ). 

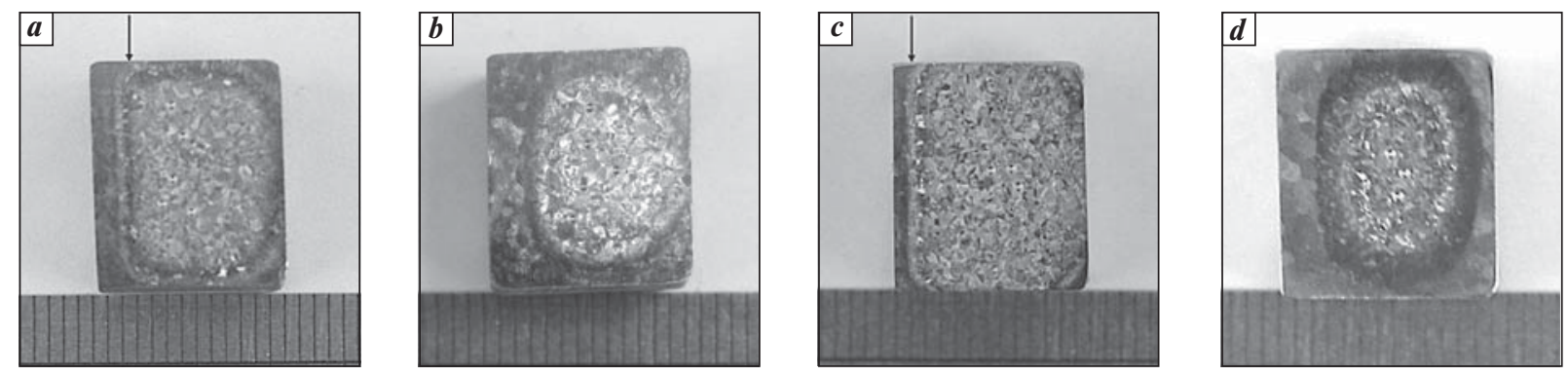

Fig. 1. The macrostructure change in depth of VT6 alloy samples after hydrogenating annealing at $800{ }^{\circ} \mathrm{C}$ up to a hydrogen concentration of $0.3 \%$ $(a, c)$ and $0.5 \%(b, d)$ with oxide $(a, b)$ and nitride $(c, d)$ barrier coating

Metallographic studies have shown that the microstructure changes after hydrogenating annealing are similar in all samples. Thus, $\left(\alpha^{\prime \prime}+\beta\right)$-structure is formed on the side free from the oxide barrier coating (Fig. 2, $a$ ). On penetrating deeper into the samples, a gradual decrease in the number of $\alpha^{\prime \prime}$-martensite plates and an increase in the number of $\alpha$-plates are observed (Fig. 2,b). At a distance of more than $5000 \mu \mathrm{m}$ the structure of the samples is already represented by $\beta$-grains surrounded by $\alpha$-border with $\alpha$-plates located inside them (Fig. 2, c). Such a structure is typical for titanium semi-finished products after annealing from $\beta$-zone.

Since in the process of hydrogenating annealing there are created the conditions under which almost all hydrogen is concentrated in a near-surface layer, then the structure transformation does not takes place over the entire cross-section of the sample, but only to a certain depth. With a rise in the added hydrogen amount from $0.3 \%$ to $0.6 \%$, smooth increase in the depth of the transformed layer is seen (Table 3).

Thus, in semi-finished products with an oxide protective coating there is formed a unidirectional gradient structure, in which the depth of the transformed structure varies from 1800 to $4000 \mu \mathrm{m}$, depending on the introduced hydrogen concentration.

Similar results have been obtained on the samples with a nitride barrier coating. The general nature of the structure change on the side free of the nitride coating is

Table 3

Influence of the type of barrier coating and the introduced hydrogen amount on the depth of its penetration into VT6 alloy samples

\begin{tabular}{|c|c|c|c|}
\hline \multirow{2}{*}{ Type of coating } & $\begin{array}{c}\text { Hydrogen } \\
\text { amount, mass } \\
\%\end{array}$ & \multicolumn{2}{|c|}{$\begin{array}{c}\text { Depth of hydrogen } \\
\text { penetration, } \mu \mathrm{m}\end{array}$} \\
\cline { 2 - 4 } & $\begin{array}{c}\text { Uncoated } \\
\text { side }\end{array}$ & $\begin{array}{c}\text { Coated } \\
\text { sides }\end{array}$ \\
\hline \multirow{2}{*}{ Oxide coating } & 0.3 & 1800 & 0 \\
\hline \multirow{2}{*}{ Nitride coating } & 0.5 & 2800 & 100 \\
\hline & 0.6 & 3000 & 1000 \\
\hline & 0.15 & 4000 & 3000 \\
\hline & 0.4 & 3800 & 0 \\
\hline
\end{tabular}

kept. Under all conditions of hydrogen addition, in the samples there is formed a unidirectional gradient structure, in which a smooth sequential change of the structures is observed: $\left(\alpha^{\prime \prime}+\beta\right),\left(\alpha^{\prime \prime}+\beta+\alpha\right),(\alpha+\beta)$ (Fig. 3). As the amount of hydrogen rises from $0.15 \%$ to $0.5 \%$, the depth of the transformed layer increases gradually from 2200 to $4500 \mu \mathrm{m}$, respectively (Table 3 ). It should also be noted that the depth of the transformed structures at the samples with a nitride protective coating is 1.5 times larger than that in the samples with an oxide protective coating, which is caused by its higher protective properties.

Analysis of the structure changes on the sides protected by an oxide or nitride barrier coating has showed that the structure of the samples that are hydrogen-charged up to the amount from $0.3 \%$ and $0.4 \%$ of hydrogen does not practically differ from the annealed condition already at a distance of $100 \mu \mathrm{m}$ from the surface and is presented by $\alpha$-plates located inside $\beta$-grains (Fig. 4, $a, c$ ). This indicates the absence of hydrogen penetration through the protective coating (Table 3). However, an increase in the

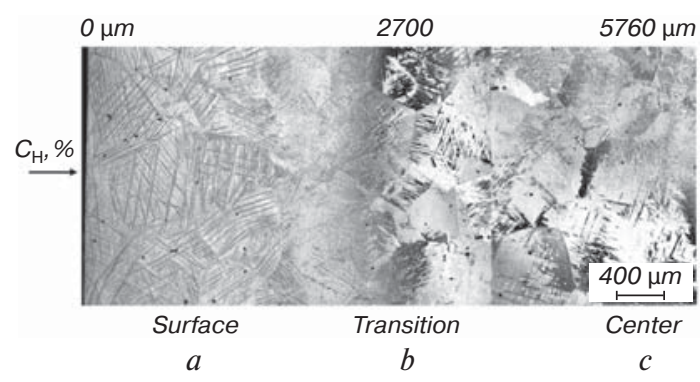

Fig. 2. The structure change in depth of a VT6 alloy sample after hydrogenating annealing at $800{ }^{\circ} \mathrm{C}$ up to a concentration of $0.4 \%$ from the side without an oxide barrier coating

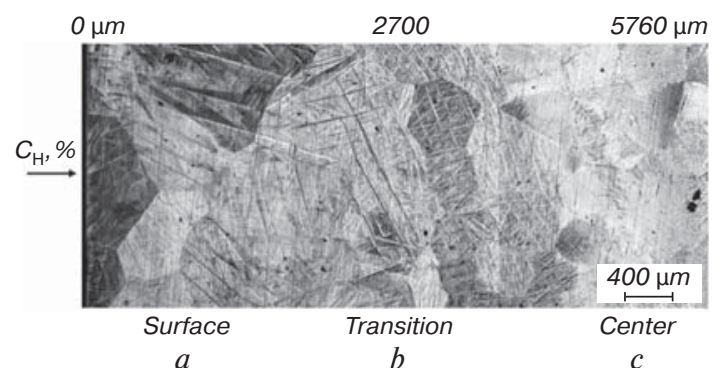

Fig. 3. The structure change in depth of a VT6 alloy sample after hydrogenating annealing at $800{ }^{\circ} \mathrm{C}$ up to a concentration of $0.4 \%$ from the side without a nitride barrier coating 

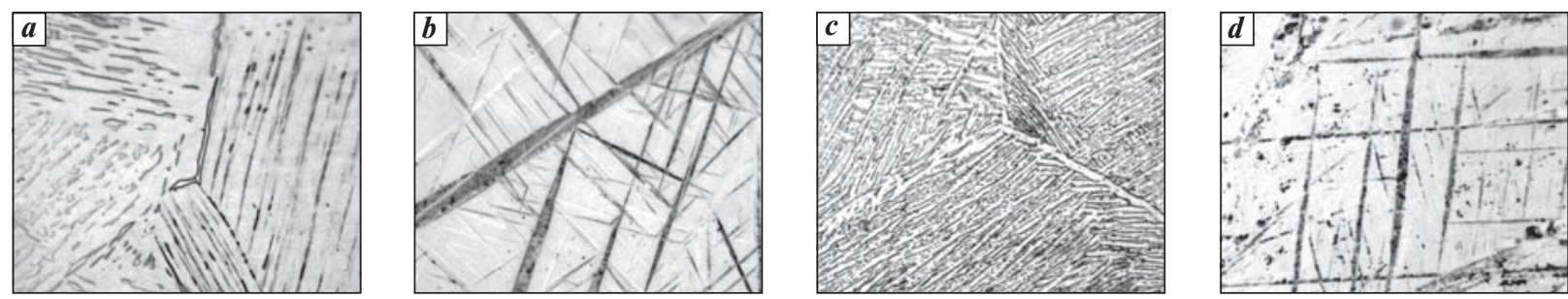

Fig. 4. Structure of VT6 alloy samples after hydrogenating annealing up to $0.4 \%(a, c)$ and $0.5 \%(b, d)$ of hydrogen at a distance of $100 \mu \mathrm{m}$ from the surface on the sides "isolated" by an oxide $(a, b)$ and nitride $(c, d)$ barrier coating

hydrogen content up to $0.5 \%$ and $0.6 \%$ leads to the appearance of $\alpha$-martensite in the structure, which remains at a significant depth from the surface of the samples (Table 3). This demonstrates a partial loss of the protective properties of the barrier coatings.

At the next stage of the work, vacuum annealing at a temperature of $625^{\circ} \mathrm{C}$ was performed to remove hydrogen up to safe amount and to form the final gradient structure. First, all the samples have been exposed to mechanical operation to remove the protective coating. Taking into account that the effectiveness of protective coatings at hydrogen amount of more than $0.4 \%$ is reduced, and at hydrogen concentrations of $0.3 \%$ the depth of the transformed structure may not be sufficient to obtain the required dynamic resistance, then the samples were subjected to vacuum annealing, preliminary being hydrogencharged up to an amount of $0.4 \%$.

The investigations have shown that on the side from which the barrier coating was removed before hydrogen addition, a $\beta \rightarrow \alpha$ transformation is in progress during the degassing process on low-temperature vacuum annealing,

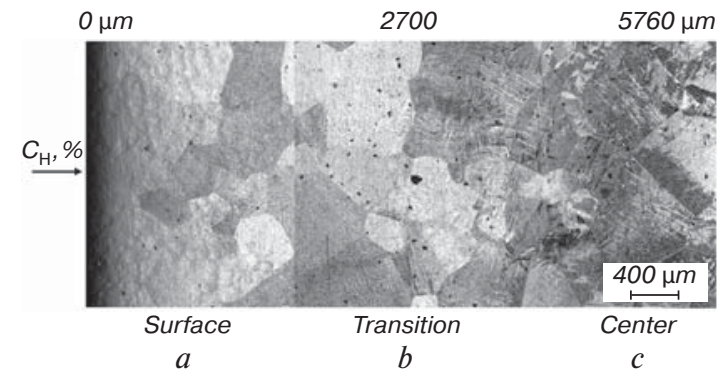

Fig. 5. The structure change in depth of VT6 alloy samples at the side without an oxide barrier coating after hydrogenating annealing up to $0.4 \%$ of hydrogen and vacuum annealing

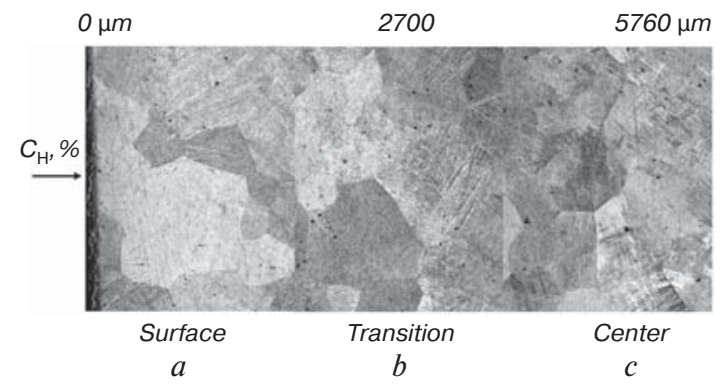

Fig. 6. The structure change in depth of VT6 alloy samples at the side without a nitride barrier coating after hydrogenating annealing up to $0.4 \%$ of hydrogen and vacuum annealing and a dispersed structure is formed in the near-surface layers (Figs. 5, $a ; \mathbf{6}, a$ ). Dispergation degree of the structural components is decreasing with the distance from the surface deep into the sample (Figs. 5, $b ; 6, b$ ), and at a depth of more than $5000 \mu \mathrm{m}$ the structure already differs little from the annealed state (Figs. 5, $c ; 6, c$ ). In this case, the hardness of the near-surface layer with a dispersed $(\alpha+\beta)$ structure is $40-41$ HRC units, and that of the inner layer with an unchanged coarse-lamellar $(\alpha+\beta)$ structure is 33-34 HRC units.

To estimate approximately the level of ballistic properties of materials with a unidirectional gradient structure, standard mechanical tests were carried out. In [23], it was found that the best correlation between the material ballistic and mechanical properties is achieved on the impact strength testing. It is not possible to produce the samples for tensile testing with a unidirectional gradient structure. Therefore, two structures have been modeled separately on the samples for tensile testing: coarse-lamellar and finely dispersed ones, whereas the samples with a unidirectional gradient structure have been impact tested only.

Analysis of the results presented in Table $\mathbf{4}$ has showed that the annealed coarse-lamellar structure provides high values of impact strength, but low values of strength. At the same time, its transformation into a fine $(\alpha+\beta)$ structure leads to a significant increase in the ultimate strength and to a drastic decrease in ductility and impact strength. The creation of a dispersed structure in the near-surface layer of the sample while keeping the coarse-lamellar structure of the inner layers provided it with increased strength and impact strength characteristics.

At the final stage of the work, the ballistic properties of VT6 alloy plates with a unidirectional gradient structure have been investigated. The plate processing technology has included the application of an oxide (plate No. 1) or nitride (plate No. 2) barrier coating, mechanical removal of it on one side for directional hydrogen introduction up to a concentration of $0.4 \%$, mechanical removal of the coating from the other sides and low-temperature vacuum annealing at $625^{\circ} \mathrm{C}$. The shots have been fired from a submachine gun, a machine gun and a sniper rifle at the front plane of the plates with ammunition of different hardness and the core blow developed energy (Table 2). An outward appearance of the front and back panels of the plates with a size of $150 \times 65 \times 12.5 \mathrm{~mm}$ after ballistic testing is shown in Fig. 7. 
Table 4

Complex of mechanical properties of VT6 alloy samples depending on processing mode

\begin{tabular}{|l|c|c|c|c|}
\multicolumn{1}{c|}{ The structure type } & $\begin{array}{c}\text { Hardness, } \\
\text { HRC surface } / \text { base }\end{array}$ & $\mathrm{KCU}, \mathrm{MJ} / \mathrm{cm}^{2}$ & $\sigma_{\mathrm{B}}, \mathrm{MPa}$ & $\delta, \%$ \\
\hline Coarse-lamellar & $33.5 / 33.5$ & 0.65 & 960 & 9 \\
\hline Finely dispersed & $41.5 / 41.5$ & 0.15 & 1150 & 5 \\
\hline $\begin{array}{l}\text { Linear from finely dispersed to coarse-lamellar } \\
\text { (barrier oxide coating) }\end{array}$ & $40.0 / 33.5$ & 0.45 & - & - \\
\hline $\begin{array}{l}\text { Linear from finely dispersed to coarse-lamellar } \\
\text { (barrier nitride coating) }\end{array}$ & $41.0 / 33.5$ & 0.50 & - & - \\
\hline
\end{tabular}

Plate 1 (barrier oxide coating)
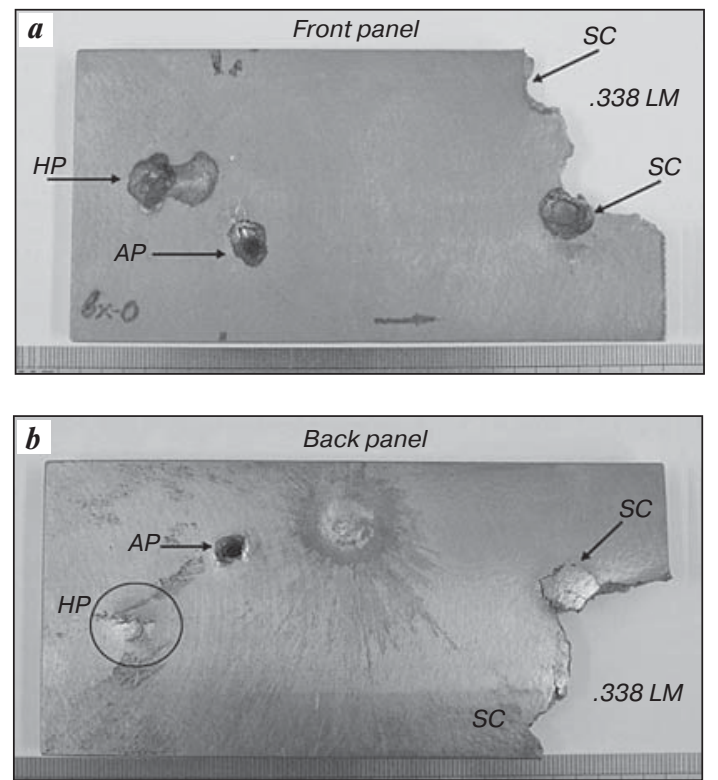

Plate 2 (barrier nitride coating)
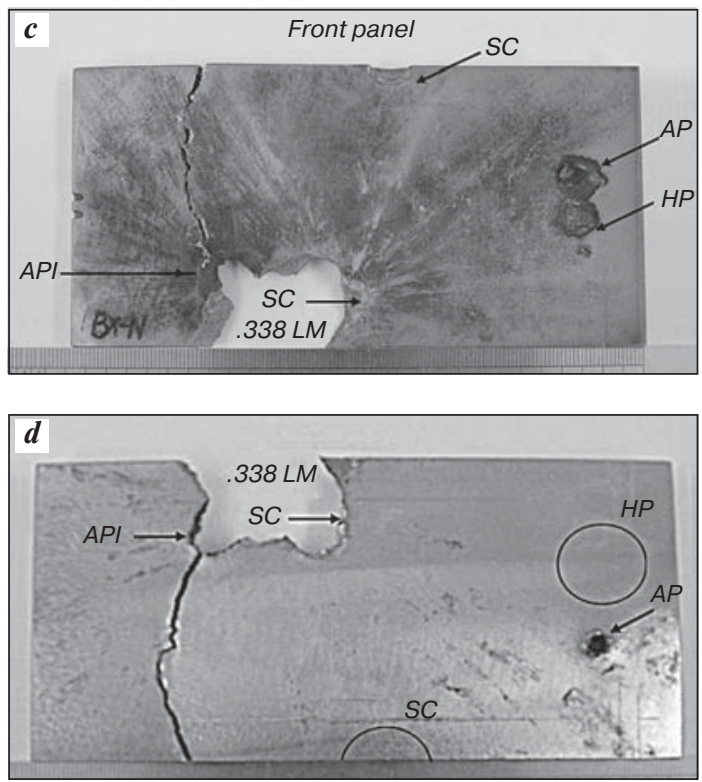

Fig. 7. Results of ballistic tests of VT6 alloy plates with a unidirectional gradient structure

Tests have shown that the plate, in which an unidirectional gradient structure was formed by the oxide barrier coating (plate No. 1) sustained firing of the high penetration bullets of 5.45- $\mathrm{mm} / \mathrm{HP}$ (series of 3 shots) and $7.62-\mathrm{mm} / \mathrm{SC}$ bullets with a steel core (single shot). It should be noted that $5.45-\mathrm{mm}$ ammunition fired a series of shots with the distance between the hit points being less than $5 \mathrm{~mm}$. On the front side of the plate, the entrance holes have an irregular shape and uneven edges, which indirectly means the destruction of the ammunition and the shot energy absorption (Fig. 7,a). On the back plane there is no through penetration (there is a small convexity with a crack) (Fig. 7,b). Fire on the plate with bullets of greater hardness and impact energy (Table $2-5.45-\mathrm{mm}$ bullets HP and $.338 \mathrm{LM}$ ) leads to a penetration. On the back panel, an output hole indicates the absence of metal resistance when interacting with the bullet. In addition, in the case of .338 LM bullets, the maximum impact pressure excess at a clash is expressed in the plate destruction.

The tested plates with a unidirectional gradient structure formed by the nitride barrier coating (plate No. 2), have showed better results compared to the plate No. 1
(Fig. 7, $c, d$ ). For example, after the fire with $5.45-\mathrm{mm} / \mathrm{HP}$ high penetration bullets (series of 3 shots) and $7.62-\mathrm{mm} /$ SC bullets with steel core (single shot), there is no through penetration and cracks on the back plane, and the plate deformation has a minimum size (Fig. 7, $d$ ). When fired with ammunition with higher characteristics (Table 4, 5.45-mm HP, 7.62-mm API and .338 LM bullets), a through penetration is observed on the back plane of the plate. The outlet hole convexity of the edges on the plate with the nitride barrier coating after the fire with a $5.45-\mathrm{mm}$ armor-piercing (AP) bullet indicates its higher resistance, but apparently, there was a little lack of surface hardness for a full blow absorption (Fig. 7, d).

The results of metallographic studies of the plates for ballistic tests are presented in Fig. 8. It has been established that the oxide coating barrier properties in the case of a larger product processing are lost because of a long stay at the temperature of hydrogen addition. This leads to hydrogen penetration from the sides protected by the barrier coating (Fig. 8, a). Evidently, this is due to a decrease in its dynamic durability index.

At the same time, the nitride coating barrier properties are also kept on the plates: there is no hydrogen 

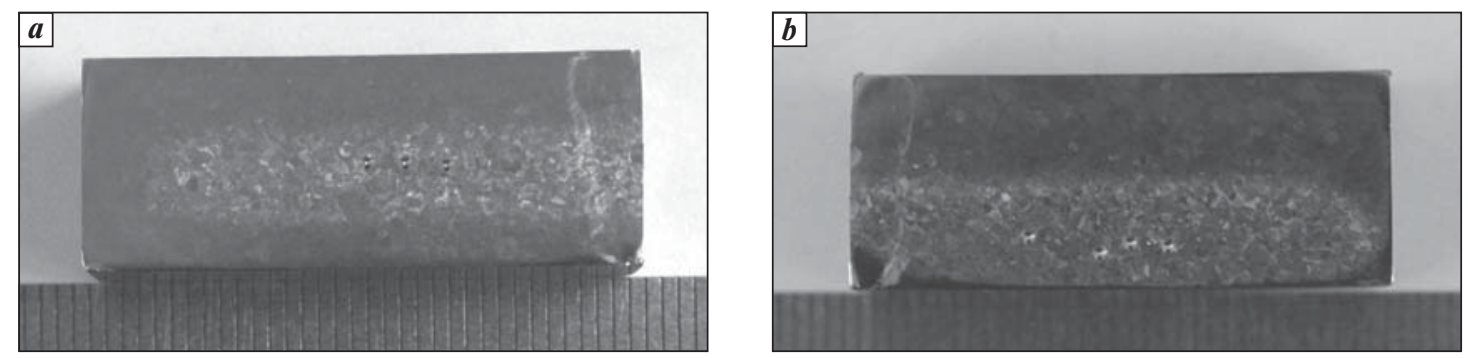

Fig. 8. Plates of VT6 titanium alloy with the application of "insulating" oxide coating layer $(a)$ and with the application of an "insulating" nitride layer $(b)$

penetration from the protected sides and the structure transformation goes unidirectionally (Fig. 8,b). However, it should be noted that low dynamic durability of the plate with the nitride coating could be connected with insufficient hardness of the near-surface layer or with the transformed structure depth.

\section{Conclusions}

1. The studies have shown that the thermal hydrogen treatment of VT6 alloy plates with an oxide or nitride coating applied on five sides allows to form a unidirectional gradient structure, which varies from a finely dispersed on one side to a coarse-lamellar on the opposite one.

2. It was found that the oxide and nitride coatings have the greatest effectiveness against hydrogen penetration up to amount of $0.4 \%$.

3. It is shown that as hydrogen content increases from $0.3 \%$ to $0.4 \%$, the transformed layer depth rises from 1800 to $2800 \mu \mathrm{m}$ and from 2200 to $4500 \mu \mathrm{m}$ for an oxide and nitride barrier coating, respectively.

4. It was demonstrated that the formation of a dispersed structure in the near-surface layers makes it possible to increase the hardness up to 41 HRC units.

5. The tests carried out have showed good dynamic durability of the plates with a linear gradient structure against 5.45-mm HP and 7.62-mm SC ammunition.

\section{Acknowledgement}

The research was carried out on equipment of the Aerospace Materials and Technologies Resource Center for collective use of Moscow Aviation Institute.

\section{References}

1. Alekseev M. O., Chistyakov E. N., Kupryunin D. G. Modern State of Armor Materials. Eksport Vooruzhenii. 2017. No. 130. pp. 50-56.

2. Petrov A. P., Shlenskiy A. G. Application of Aluminum Alloys in Armored Protection of Aircraft. Technology of Light Alloys. 2019. No. 3. pp. 76-85.

3. Mylnikov V. V., Abrosimov A. A., Romanov I. D., Romanov A. D. The Analysis of Materials and Their Properties Applied to Means Individual Armored Protection. Advances in Current Natural Sciences. 2014. No. 9-2. pp. 143-147.

4. Grigoryan V. A., Kobylkin I. F., Marinin V. M., Chistyakov E. N. Materials and Protective Structures for Local and
Individual Armoring. Moscow : Izdatelstvo RadioSoft, 2008. $406 \mathrm{p}$.

5. Anastasiadi G. P., Silnikov M. V. Operability of Armor Materials. St. Petersburg : Asterion, 2004. 624 p.

6. Konovalov S., Komissarova I., Ivanov Y., Gromov V., Kosinov D. Structural and Phase Changes under Electropulse Treatment of Fatigue-Loaded Titanium Alloy VT1-0. Journal of Materials Research and Technology. 2019 . Vol. 8, Iss. 1. pp. 13001307. DOI: 10.1016/j.jmrt.2018.09.008

7. Xie L., Liu C., Song Y., Guo H., Wang Z., Hua L., Wang L., Zhang L.-C. Evaluation of Microstructure Variation of TC11 Alloy After Electroshocking Treatment. Journal of Materials Research and Technology. 2020. Vol. 9, Iss. 2. pp. 2455-2466. DOI: 10.1016/j.jmrt.2019.12.076;

8. Kolachev B. A., Ilyin A. A., Nosov V. K., Mamonov A. M. Achievements of Hydrogen Technology of Titanium Alloys. Technology of Light Alloys. 2007. No. 3. pp. 10-26.

9. Ilyin A. A., Skvortsova S. V., Mamonov A.M., Kolerov M. Yu. Influence of Hydrogen on Phase and Structural Transformations in Titanium Alloys of Different Classes. Physicochemical Mechanics of Materials. 2006. No. 3. pp. 33-39.

10. Senkevich K. S., Skvortsova S. V., Kudelina I. M., Knyazev M. I., Zasypkin V. V. Effect of a Microstructure and Surface Hydrogen Alloying of a VT6 Alloy on Diffusion Welding. Russian Metallugry (Metally). 2014. Iss. 1. pp. 66-70.

11. Mamonov A. M., Safaryan A. I., Agarkova E. O., Zhilyakova M. A. Analysis of the Possibilities of Transformation of Lamellar Structures of Titanium and Zirconium Alloys by Methods of Thermohydrogen Treatment. Metal Science and Heat Treatment. 2018. Vol. 60, Iss. 1-2. pp. 80-88.

12. Ovchinnikov A., Skvortsova S., Mamonov A., Yermakov E. Influence of Hydrogen on Plastic Flow of the Titanium and Its Alloys. Acta Metallurgica Slovaca. 2017. Vol. 23, Iss. 2. pp. 122-134.

13. Ilyin A. A., Skvortsova S. V., Spector V. S., Kudelina I. M., Mamontova N. A. Formation of a Gradient Structure in Titanium Alloy by Thermal Hydrogen Treatment. Technology of Light Alloys. 2011. No. 2. pp. 37-41.

14. Skvortsova S. V., Spektor V. S., Kudelina I. M., Neiman A. P., Mamontova N. A. Formation of a Gradient Structure in VT6 alloy Under Thermal Hydrogen Treatment. Titan-2011 in CIS : Proceedings of the International Conference. Lvov. 2011. pp. $375-377$.

15. Gvozdeva O. N., Shalin A. V., Stepushin A. S. The Correlation Among Chemical Composition, Structure and Mechanical 
Properties in Ttanium Alloys for the Elements with Increased Dynamic Ability. IOP Conference Series: Materials Science and Engineering. Vol. 709, Iss. 1. 022082. DOI: 10.1088/1757-899x/ $709 / 2 / 022082$

16. Skvortsova S. V., Gvozdeva O. N., Shalin A. V., Stepushin A. S. Linear Gradient Structure Creation in VT6 Titanium Alloy. Titan. 2019. No. 3. pp. 25-31.

17. Ilyin A. N., Kolachev B. A., Polkin I. S. Titanium Alloys. Composition, Structure, Proreties. Reference Book. Moscow: VILS - MATI, 2009. $520 \mathrm{p}$.

18. GOST R 50744-95. Armor Clothes. Classification and General Technical Requirements. Moscow: Izdatelstvo standartov, $2003.32 \mathrm{p}$.

19. GOST R 50963-96. Armor Protection Cars. General Technical Requirements. Moscow: Izdatelstvo standartov, 2003. $30 \mathrm{p}$.

20. Lukina E., Kollerov M., Meswania J., Panin P., Khon A., Blunn G. The Influence of TiN and DLC Deposition on the
Wear Resistance of Nitinol - Ti6Al4V Combination for the Medical Application. Materials Today: Proceedings. 2017. Vol. 4, Iss. 3. pp. 4675-4679.

21. Skvortsova S. V., Spector V. S., Sarychev S. M., Orlov A. A. Influence of Surface Structures on Torque of VT6 Alloy Cortical Screws. IOP Conference Series: Materials Science and Engineering. 2020. Vol. 971. 032030. DOI: 10.1088/1757-899x/ $971 / 3 / 032030$

22. Mamonov A. M., Sarychev S. M., Slezov S. S., Chernyshova Yu. V. Effect of Vacuum Ion-Plasma Treatment on Surface Layer Structure, Corrosion and Erosion Resistance of Titanium Alloy with Intermetallic a2-Phase. Metal Science and Heat Treatment. 2018. Vol. 60, Iss. 5-6. pp. 290-296.

23. Illarionov A. G., Zloba A. V., Leder M. O., Stepanov S.I., Berestov A. V., Popov A. A. Structure, Mechanical and Ballistic Properties Formation in Heat-Treated Sheets of VST2 Alloy with Various Compositions. Titan. 2018. No. 2. pp. 13-18. 